\title{
Case Report: Treating Cryptococcal Meningoencephalitis with Chinese Herbal Medicine Based on Macro Natural Law of Traditional Chinese Medicine
}

\author{
Bian Wei ${ }^{1}$, Wang Huanqun ${ }^{2}$, , Zou Weiwu ${ }^{2}$, Gan Ting ${ }^{2}$ \\ ${ }^{1}$ Department of Rehabilitation, Chongqing Yongchuan Hospital of Traditional Chinese Medicine, Chongqing, China \\ ${ }^{2}$ Department of Neurology, Chongqing Yongchuan Hospital of Traditional Chinese Medicine, Chongqing, China \\ Email address: \\ 2380139344@qq.com (Bian Wei), 554132994@qq.com (Wang Huanqun) \\ ${ }^{*}$ Corresponding author
}

To cite this article:

Bian Wei, Wang Huanqun, Zou Weiwu, Gan Ting. Case Report: Treating Cryptococcal Meningoencephalitis with Chinese Herbal Medicine Based on Macro Natural Law of Traditional Chinese Medicine. International Journal of Chinese Medicine. Vol. 4, No. 2 , 2020 , pp. $27-31$. doi: $10.11648 / j . i j c m .20200402 .13$

Received: May 20, 2020; Accepted: June 8, 2020; Published: June 20, 2020

\begin{abstract}
Background: Over the past few decades, Expansion, Cryptococcus infection. Has become a worldwide Common fungal infections. Cryptococcus prevention has many difficulties in clinical application. Survivors Neurological sequelae are also common Cryptococcal Meningoencephal, CM. In China, Traditional Chinese Medicine tends to been used for poor fungal treatment or sequelae. Case presentation: We present a 47-year-old patient with cryptococcal encephalitis who's clinical manifestations are atypical, and it is easy to misdiagnose. The first symptom was headache after tooth extraction, followed by fever. The diagnosis was confirmed 6 months after the onset of the disease. After antifungal treatment for 18 days, Headache and fever not reduced and multiple adverse effects such as impaired internal organs. The use of antifungal therapy has serious adverse reactions and poor treatment effects. When the disease is in critical condition, the modern medical antifungal treatment is ineffective and resistant to help. Using traditional Chinese medicine theory, it acknowledges the harmonious unity between man and nature, instead of looking for better resistance Fungal drugs, but by changing the internal environmental stability of the body, after 5 days of initial treatment, the patient no longer had fever, headache, snore, appetite restored and normal bowel movements, the nervous system function gradually recovers. No fever or headache occurred within 5 months, neurological function gradually recovered, head MRI improved, and cerebrospinal fluid culture was negative. After 7 months, the patient still had no fever, headache, snore, he can take care of himself, normal language expression can be done, farm work at home, one person can do food shopping and cooking, etc., limb muscle strength is normal, muscle tension is not high, No positive neurological examination. Conclusion: Traditional Chinese medicine modalities may be considered for treatment When western medicine treatment of cryptococcal encephalitis is not effective, based on appropriate syndrome pattern assessment.
\end{abstract}

Keywords: Cryptococcal Meningoencephalitis, Traditional Chinese Medicine, Chinese Herbs

\section{Introduction}

Background: Over the past few decades, Expansion, Cryptococcus infection [1] has become a worldwide Common fungal infections [2-3]. Up to 1 million [4] cryptococci every year New cases of meningitis infection, even after 3 months of treatment624 700 deaths still [5]. The disease is often exacerbated [6], the prognosis is poor, and the mortality rate is high [7]. Suffer Often die within a few months without treatment [8-9], with an average duration of about 6 months.
Cryptococcus [10] prevention has many difficulties in clinical application. Survivors Neurological sequelae [11] are also common Cryptococcal Meningoencephal, CM. The signs of high intracranial pressure, meningeal irritation and cranial nerves impairment are the main clinical manifestations of cryptococcal meningitis, while seizures, hemiplegia, mental disorders and ataxia can occur when the brain parenchyma is involved. Cryptococcal meningitis and/or cryptococcal meningoencephalitis is easy to be misdiagnosed, Combined, long term antifungal therapy should be used immediately in 
confirmed cases, and surgery operations can be used in necessity to improve outcomes. For those with poor treatment effects or large side effects, Chinese medicine treatment can be an option.

We present a case of a man who developed Cryptococcal Meningoencephalitis following Tooth extraction, treated successfully with traditional Chinese herbs.

\section{Case Presentation}

A 47-year-old Chinese man presented at Chongqing Yongchuan Hospital of Traditional Chinese Medicine Neurology Clinic in July 2, 2019 complaining of fever, headache, hiccup frequency, On December 29, 2018, the patient suffered intermittent headaches after tooth extraction, mainly at night, with pain tolerable, no fever, no attention, and no treatment. The patient then went to the Yongchuan Hospital affiliated to Chongqing Medical University on June 02, 2019. Cerebrospinal fluid measurement: glucose $<1.1$ mmol, protein quantification $2.53 \mathrm{~g} / 1$; head MRI: left basal ganglia and bilateral frontal cortex multiple Focus, consider the possibility of infection, bilateral frontal lobe multiple ischemic focus, consider intracranial infection, suppurative meningitis is more likely, tuberculous meningitis can not be ruled out. After vancomycin resistance to infection, the patient developed a disturbance of consciousness. A re-examination of the head CT showed a new lesion in the right thalamus region, and a cerebrospinal fluid culture showed a fungal infection. The patient was then hospitalized at Chongqing Xinqiao Hospital on June 10, 2019. A craniocerebral MRI was performed: multiple abnormally enhanced images of bilateral basal ganglia, thalamus, and brainstem areas were considered, and infectious lesions should be considered. Cerebrospinal fluid culture can be found Cryptococcus neoformans; sputum culture: Klebsiella pneumoniae. After admission, she was given $250 \mathrm{ml}$ of flucytosine injection $\mathrm{q} 8 \mathrm{~h}$ (from June 11, 2019) and amphotericin B liposome for injection (June 15-18, 2019, starting dose 50mg, 10mg daily increase, On June 19, 2019, $60 \mathrm{mg}$ was maintained on July 01, 2019) symptomatic treatment such as antifungal, dehydration and lowering intracranial pressure, due to adverse reactions such as multiple visceral function impairment, family members asked to be discharged to our hospital to continue treatment, Families strongly refused antifungal treatment after admission, and fever and headache persisted after 8 days of basic treatment and TCM Dissipating Dampness and nourishing yin, and symptoms did not decrease.

\section{Diagnosis and Treatment}

Traditional Chinese medicine (TCM) findings revealed he was absence of vitallity, aversion to cold, Repeated fever every day, body temperature is between 38-40 degrees, worse at night, no sweat,, Thirst for hot drinks. Red tongue, white tongue coating, dry, tight and greasy.

Table 1. Summary of TCM diagnostics, and herbal formulas for each visit.

\begin{tabular}{|c|c|c|}
\hline Visit & TCM diagnostics & Herbal formula \\
\hline $\begin{array}{l}1 \text { (July 11, } \\
2019)\end{array}$ & $\begin{array}{l}\text { the patient has a headache and a painful face. He presses his head with his } \\
\text { healthy hand. His body temperature is between } 38-40 \text { degrees. It's heavy at } \\
\text { night. He has hiccups, difficulty in extending his tongue, sleepiness, and can't } \\
\text { shout loudly. His eyes can turn to the direction of sound. His speed is slow, and } \\
\text { his reaction is poor. He is unwilling to communicate more. His tongue is red, } \\
\text { tongue coat is dry and greasy, his right cun pulse is large, and his right Guan } \\
\text { pulse is weak. }\end{array}$ & $\begin{array}{l}\text { fried melon seeds } 20 \mathrm{~g} \text {, scutellaria baicalensis } 20 \mathrm{~g} \text {, bile } \\
\text { Nanxing } 20 \mathrm{~g} \text {, white scallion } 20 \mathrm{~g} \text {, duckweed } 10 \mathrm{~g} \text {, bran } \\
\text { fried atractylodes wilfordii } 15 \mathrm{~g} \text {, forsythia } 15 \mathrm{~g} \text {, French } \\
\text { pinellia } 10 \mathrm{~g} \text {, black sage } 30 \mathrm{~g} \text {, artemisia annua } 1520 \mathrm{~g} \text {, } \\
\text { Dendrobium } 30 \mathrm{~g} \text {, Peony Peel } 15 \mathrm{~g} \text {, Uncaria serrata } \\
30 \mathrm{~g} \text {, and } 20 \mathrm{~g} \text { Qingyan Stone are fried for } 4 \text { hours with } \\
100 \mathrm{ml} \text { gastric tube. }\end{array}$ \\
\hline $\begin{array}{l}3 \text { (July 14, } \\
2019)\end{array}$ & $\begin{array}{l}\text { The patient's headache was relieved, and there were some mild headaches. The } \\
\text { frequency of pressing the head with his hands was reduced, and his } \\
\text { consciousness improved. He could actively turn his head to the direction of } \\
\text { light and sound. There were some interactive expressions on his face. The limb } \\
\text { temperature is not high, the temperature of the abdomen and the armpit is high, } \\
\text { the mouth is dry and thirsty, and the cold drink is taken, and the yellow stool is } \\
\text { relieved } 3 \text { times. The right cun-pulse and guan-pulse is weak press, and the } \\
\text { tongue is red with yellow and greasy. coating. }\end{array}$ & $\begin{array}{l}\text { Raw Rehmannia 30g, Scrub 30g, Duckweed } 10 \mathrm{~g} \text {, } \\
\text { Bupleurum } 15 \mathrm{~g} \text {, Artemisia annua } 15 \mathrm{~g} \text {, Gypsum } 30 \mathrm{~g} \text {, } \\
\text { Zhimu 9g, Dendrobium } 20 \mathrm{~g} \text {, Zhejiang Fritillaria } 20 \mathrm{~g} \text {, } \\
\text { Bran Fried Amaranth Seed } 10 \mathrm{~g} \text {, Bran Fried } \\
\text { Atractylodes Rhizoma } 20 \mathrm{~g} \text { Peony skin } 15 \mathrm{~g} \text {, Scutellaria } \\
\text { baicalensis } 10 \mathrm{~g} \text {, turmeric } 20 \mathrm{~g}\end{array}$ \\
\hline $\begin{array}{l}\text { (July } 14,2019) \\
\text { Night round }\end{array}$ & $\begin{array}{l}\text { The patient's temperature was } 38-38.8 \text { degrees that night, and his consciousness } \\
\text { was clearer than before. The limbs were no longer cold and the chest and } \\
\text { abdomen were hot. The limbs began to heat up. The pulse was stronger than the } \\
\text { previous day and the entire body was warmed up. }\end{array}$ & \\
\hline $\begin{array}{l}4 \text { (July 15, } \\
2019)\end{array}$ & $\begin{array}{l}\text { At } 7 \text { am, the patient no longer had fever, no headache, and was able to feed a } \\
\text { few porridges. He did not have fever until } 5 \text { pm, and his consciousness } \\
\text { improved. He could actively turn his head to the direction of light and sound. } \\
\text { The body temperature was around } 37 \text { degrees, and the right guan was weak. }\end{array}$ & $\begin{array}{l}\text { Uncaria lucidum } 30 \mathrm{~g} \text { (Decocting Later), windproof } \\
9 \mathrm{~g} \text {, Ophiopogon } 18 \mathrm{~g} \text {, bile Nanxing } 15 \mathrm{~g} \text {, Dendrobium } \\
30 \mathrm{~g} \text {, Beisha ginseng } 30 \mathrm{~g} \text {, calcined magnet } 10 \mathrm{~g} \text {, } \\
\text { Bupleurum } 9 \mathrm{~g} \text {, black ginseng } 30 \mathrm{~g} \text {, Kudzu root } 45 \mathrm{~g} \text {, } \\
\text { bran stir-fried atractylodes root } 15 \mathrm{~g} \text {, loquat bitter } \\
\text { almond } 15 \mathrm{~g} \text {, scallion } 6 \mathrm{~g} 20 \mathrm{~g} \text { white peony, } 10 \mathrm{~g} \text { peony } \\
\text { skin, } 10 \mathrm{~g} \text { forsythia }\end{array}$ \\
\hline
\end{tabular}




\begin{tabular}{|c|c|c|}
\hline Visit & TCM diagnostics & Herbal formula \\
\hline $\begin{array}{l}\text { (July } 15,2019) \\
\text { Night round }\end{array}$ & $\begin{array}{l}\text { No fever that night, between } 36-37 \text { degrees, no headaches, good spirits, simple } \\
\text { answers to questions, family members are very satisfied. }\end{array}$ & \\
\hline $\begin{array}{l}5 \text { (July 16, } \\
2019 \text { ) }\end{array}$ & $\begin{array}{l}\text { The patient did not complain of headaches, did not show elevated body } \\
\text { temperature, was mentally conscious, could stare at the speaker, was conscious, } \\
\text { actively shook his head and nodded, he could sit up into porridge, a smile } \\
\text { appeared on his face, he could simply answer questions, and still need urine } \\
\text { drainage Tube export, normal stool }\end{array}$ & $\begin{array}{l}\text { Uncaria sylvestris } 30 \mathrm{~g} \text { (Decocting Later), North } \\
\text { American ginseng } 30 \mathrm{~g} \text {, windproof } 9 \mathrm{~g} \text {, French pinellia } \\
9 \mathrm{~g} \text {, gypsum } 15 \mathrm{~g} \text {, calcined magnet } 10 \mathrm{~g} \text {, black ginseng } \\
30 \mathrm{~g} \text {, peony peel } 15 \mathrm{~g} \text {, scutellaria baicalensis } 9 \mathrm{~g} \text {, white } \\
\text { scallion } 20 \mathrm{~g} \text {, mint } 9 \mathrm{~g} \text {, lower bitter almond } 15 \mathrm{~g} \text {, green } \\
\text { Artemisia annua } 15 \mathrm{~g} \text {, bran stir-fried atractylodes } \\
\text { rhizome } 15 \mathrm{~g} \text {, bile Nanxing } 18 \mathrm{~g} \text {, forsythia } 10 \mathrm{~g}\end{array}$ \\
\hline $\begin{array}{l}6 \text { (August 02, } \\
\text { 2019) }\end{array}$ & $\begin{array}{l}\text { Cerebrospinal fluid culture: negative. The patient was hospitalized for the next } \\
\text { two months without fever, headache, or hiccups. He could eat dry meals and } \\
\text { communicate with people around him. His eyes were better than before, his } \\
\text { body turned freely. The nervous system function gradually recovered. After one } \\
\text { month, the urinary tube was pulled out, and it was able to urinate on its own } \\
\text { without using diapers. }\end{array}$ & \\
\hline
\end{tabular}

Disease follow-up

After 4 months, the patient still did not have fever, headache, hiccups, diet, general life, he can take care of themselves, general language expression, more complex thinking and expression, can not work. After 7 months, the patient still has no fever, headache, hiccups, good diet, normal bowel movements, he can take care of himself, general language expression, simple farm work at home, one person can go to a distant place alone, one can buy food Cooking etc.

\section{Analysis}

1. Macro natural law [12] of traditional Chinese Medicine

The use of traditional Chinese medicine treatment saves lives after the antifungal treatment is ineffective. The success of traditional Chinese medicine does not lie in finding better antifungal drugs. Patients feel that the fungal-induced inflammatory response is not effective with antibiotics. We can take another way, for human The new Cryptococcus is the enemy, but to eliminate it, but the enemy is weak and I can't destroy it. We can choose to compromise. We can ask it to go out and tell it that it is not suitable for it by changing its own environment. Please make it suitable for it. Go where it grows, give it a way out, don't mess with it, get along with it with awe.

For nature, microorganisms and humans are equal [13].

They both have a meaning of existence [14]. We all enjoy the glory of the sun. Nature does not give humans the right to kill and kill microorganisms. All living things have their own laws. Natural choice. Perhaps the invention and use of antibiotics has made a huge contribution to human beings, but the current abuse of antibiotics has caused many bacteria to develop severe drug resistance, and bacteria can develop drug resistance much faster than humans can develop new drugs. The artificial reversal will only succeed for a while. We use antibiotics today, and the more we use to grow bacteria, the faster the bacteria become more resistant to drugs. The original antibiotics and bacterial mutations are resistant to antibiotics. In the arms race, humans will inevitably fail, because the bacteria mutate fast and our drugs can't keep up with its changes. When the enemy is strong and we are weak, we choose the golden mean. The golden mean is derived from the traditional Chinese culture and various forces are maintained. This philosophical thinking comes from the wisdom of the survival of the integration of heaven and human in ancient China. However, in order to adapt to the new environment, it should be indisputable. Tao Te Ching said: The highest good is like that of water. The goodness of water is that it benefits the ten thousand creatures; yet itself does not scramble, but is content with the places that all men disdain. It is this that makes water so near to the Way. And if men think the ground the best place for building a house upon, If among thoughts they value those that are profound, If in friendship they value gentleness, In words, truth; in government, good order; In deeds, effectiveness; in actions, timeliness. In each case it is because they prefer what does not lead to strife, And therefore does not go amiss. TCM will find a way out of microorganism and get it back where it is, In this way, we keep the balance of Nature.

2. Chinese culture [15]: coexisting instead of anti

In this case, the use of Chinese medicine to treat fungi is not forcibly killing him and clearing him. Not focusing on people, but focusing on nature, focusing on adjusting the internal balance of the human body, helping each other, coexisting,. All animals and plants are the environment in which humans live. We must not destroy it arbitrarily. We should work with them, live together, and live together.

Chinese medicine keeps the balance of yin and yang of the body in a moderate state. The patient has an imbalance of yin and yang in the body due to infection. The Chinese word "inflammatory" is two fires, indicating that there are more fires, where the fires come from, and the sun and everything grow Lean on the sun. Microbes exist in the world. They grow in the most suitable place under the action of the sun. The infection of the human body is also because the internal environment creates a microbial environment, so the infection symptoms and systemic reactions come to the human body.

Let the body of this small universe stay alive and maintain a state of vaporization. The disease has nothing to do with the microbes themselves and is related to their environment. The Chinese saying:"Asked ditch that is clear like this for has the source running water". For example, an apple is prone to 
mold if placed in a plastic pocket. If it is placed in a ventilated place, The place where it is not easy to break, a cup of water in the cup for a few days will stink because there is no flowing water. If you put a seed in the water and take root, the cup of water will not smell, and the water will not smell. It is not rotten, and the hub is not stubborn. The ground is covered by clouds, and the weather is rainy. It remains active. The "live" state called another name "immunity" in TCM culture is Interdependence between Yin and Yang, A relationship between Yin and Yang that each takes the other as the foundation for its own existence.

3. Theoretical point of view of traditional Chinese medicine: This disease can belong to the Epidemic Febrile disease of traditional Chinese medicine. If Essence is not stored in winter, and Epidemic Febrile disease must be in spring: The patient had experienced symptoms of warmth and evil when the winter was cold at this time (December 29, 2018): intermittent headaches. Defensive Qi is closed, and the Yin Essence is depressed:

When the condition is critical, grasp the relationship between Eliminating Pathogenic Factors and Strengthening Anti-Pathogenic Qi: The Qi is sufficient in the Yangming channels, which is caused by pathogenic heat invasion in Yangming meridians and Stomach-Yin Deficiency, Stagnation of Wood turning into fire, invasion of the Lung by fire, and insufficiency of Kidney-Essence, in this way, Extreme Phlegm-Fire and Deficiency Yin lead to the dissociation of Yin and Yang, Separation of Yin and Yang tends to disappear respectively because of complete breakdown of balance between Yin and Yang, which is caused either by extremely hyperactive side eradicating the other, or the solstitial exhaustion of one side leaving nothing for the other to depend upon, so it floats outwards. so that the symptoms of fever, headache and hiccup can be eliminated. In this critical condition, to stabilize the Qi of the Middle Energizer Dysfunction of the spleen and stomach, free flow of liver Qi, distributing the clear Lung Qi.

At the first vist, the patient had fever, hiccups, headaches, difficulty in extending the tongue, His tongue is red, tongue coat is dry and greasy, his right cun pulse is large, and his right Guan pulse is weak.. The characteristics of Extreme Phlegm-Fire and Deficiency Yin are shown; Taking into account the sputum heat and Deficiency Yin of the patient, from the perspective of "Macro natural law of traditional Chinese Medicine" theory analysis, Therefore, Ophiopogon japonicus, Xuanshen and Dendrobium are used to nourish the stomach yin and protect the function of the spleen and stomach in transformation. Duckweed, Forsythia, Artemisia annua eliminate heat of Nutritive Phase through Qi Phase. Danpi and Baiji diarrhea clear Heat from Nutritive Phase. Gou Teng clear Heat and Extinguishing Wind. Stir-fried melon dumplings, scutellaria baicalensis, bile Nanxing, blue ochre, bran-fried atractylodes root, pinellia pinellia, clear Metal and Pacify Fire. In the second visit, rhubarb, bran stir-fry, mirabilite, mirabilite, diarrhea purge Fire and Quick ly Purgate to Preserve Yin.

The problems of headache and hiccup were mainly solved in the first and second consultations, but the fever did not change significantly. Including the high Armpit temperature, The patient's chest and abdomen are hot while the limbs are cold, in the first visit we Eliminated Heat of Nutritive Phase through Qi Phase, the second visit we clear heat of Yangming $\mathrm{Fu}$ organ, in the third visit we clear heat of Yangming meridian. the limbs began to warm up. The Qi in upward, downward, outward and had been restored, and the Yang Qi could spread all over the body. After four visits, the patient did not have fever, headache, and hiccups. he could have some porridge, and later treatment to maintain the stomach qi, hide the kidney essence, and the whole body's air-conditioning can flow unobstructed.

\section{Conclusion}

Traditional Chinese medicine modalities may be considered for treatment When western medicine treatment of cryptococcal encephalitis is not effective, based on appropriate syndrome pattern assessment.

It can be seen from this that the TCM Clinical treatment should pay attention to the QI movements, to regenerate the vitality, and to pay attention to the important role of gas in the flow of vitality. In the course of treatment, adjust the drugs in time according to the changes in the condition, grasp the strength of the medication, and keep the balance of Ying and Yang.

A Chinese saying:Horizontal view of Chengfeng on the side of the ridge, the distance is different. Do not know the true face of the mountain, only in this mountain. All things has itself law. Man's backspin only happen temporarily, so without rightor wrong.

Archimedes: "Give me a place to stand on, and I can move the earth."The place is the way how we keep the balance of Natrue. "To Cure Sometimes, To Relieve Often, To Comfort Always". The highest realm of treatment is Coexist instead of anti.

\section{Consent for Publication}

Patient consent was obtained and is available from this journal's editorial office.

\section{Competing Interests}

The authors have no conflicts of interest to declare.

\section{Authors' Contributions}

Bian wei: patient data collection, background research, Wang huanqun: treatment recording writing; Gan ting:Record the healing process; Zou weiwu: therapeutic assessment; Bian wei: performed treatments, overall responsibility. All the authors read and approved the final report.

\section{Acknowledgements}

The authors are grateful for the support of Chongqing 
Yongchuan Hospital of Traditional Chinese Medicine.

The research of this subject is funded by the special fund of Chongqing Science and Technology Bureau of Yongchuan District. The approval number of this subject is: Ycstc, 2019 nb0230.

\section{References}

[1] Scriven JE, Graham LM, Schutz C, et al. The CSF immune response in HIV-1-associated cryptococcal meningitis:macrophage activation, correlates of disease severity, and effect of antiretroviral therapy [J]. J Acquir Immune Defic Syndr, 2017, 75: 299-307.

[2] Park BJ, Wannemuehler KA, Marston BJ, et al. Estimation of the current global burden of cryptococcal meningitis among persons living with HIV / AIDS [J]. AIDS, 2009, 23 (4): 525-530.

[3] Husain S, Wagener MM, Singh N. Cryptococcus neoformans infection in organ transplant recipients: variables influencing clinical characteristics and outcome [J]. Emerg Infect Dis, 2001, 7 (3): 375-381.

[4] Oladele RO, Denning DW. Burden of serious fungal infection in Nigeria [J]. West Afr J Med, 2014, 33 (2): 107-114.

[5] Shahapur PR, Bidri RC. Recent trends in the spectrum of opportunistic infections in human immunodeficiency virus infected in-dividuals on antiretroviral therapy in South India [J]. J Nat Sci Biol Med, 2014, 5 (2): 392-396.

[6] Shi M, Mody CH. Fungal infection in the brain: what we learned from intravital imaging [J]. Front immunal, 2016, 7: 292.
[7] Tseng HK, Huang TY, Wu AY, et al. How cryptococcus interacts with the blood-brain barrier [J]. Future Microbiol, 2015, 10 (10): 1669-82.

[8] Kambugu A, Meya DB, Rhein J, et al. Outcomes of cryptococcal meningitis in Uganda before and after the availability of highly active antire-troviral therapy [J]. Clin Infect Dis, 2008, 46 (11): 1694-1701.

[9] Carlson RD, Rolfes MA, Birkenkamp KE, et al. Predictors of neurocognitive outcomes on antiretroviral therapy after cryptococcal meningitis: Aprospective cohort study [J]. Metab Brain Dis, 2014, 29 (2): 269-279.

[10] Barluzzi R, Brozzetti A, Mariucci G, et al. Establishment of pro-tective immunity against cerebral cryptococcosis by means of an avirulent, non melanogenic Cryptococcus neoformans strain [J]. J Neuroimmunol, 2000, 109 (2): 75-86.

[11] Devi SJ, Schneerson R, Egan W, et al. Cryptococcus neoformans serotype A glucuronoxylomannan-protein conjugate vaccines: synthesis, characterization, and immunogenicity [J]. Infect Immun, 1991, 59 (10): 3700-3707.

[12] Zhu Shine. The difference and blend of Chinese and Western medicine [M]. Beijing: People's Medical Publishing House, $2000.124,255$

[13] Xing Yurui Editor. Basic Theory of Traditional Chinese Medicine [M]. Shaanxi: Shaanxi Science and Technology Press, 2005: 1

[14] Man Xi refute. Chinese medicine-a unique science [J]. Zhejiang Journal of Traditional Chinese Medicine, 1980, 15 (11): 33

[15] Sun Guangren. Basic Theory of Chinese Medicine [M]. Beijing: Beijing Chinese Medicine Press, 2007 (1): 46-52. 